\title{
How often is NIDDM complicated with non-diabetic renal disease?
}

\section{An analysis of renal biopsies and the literature}

\author{
S. O Isen, C.E.M ogensen \\ U niversity H ospital Århus, Institute of Pathology and D epartment M (D iabetes and E ndocrinology), A rhus, D enmark
}

Summary A ccording to extensive autopsy studies, non-diabetic renal disease seems to be rare in diabetes mellitus, but recent publications suggest a significant prevalence of non-diabetic renal disease in noninsulin-dependent diabetic (NIDDM) patients, especially in the absence of retinopathy. The purpose of this study was to evaluate the prevalence of non-diabetic renal disease in NID D M patients in renal biopsies from clinical practice, in patients suspected of having non-diabetic renal disease. In addition we systematically reviewed the literature. Biopsies were evaluated at the U niversity D epartment of Pathology, A arhus, D enmark, but had been collected at several departments of nephrology. In total 33 consecutive biopsies were available from 1988-1995 (mean age of patients: 62 years (range 39-75) (mean known diabetes duration 8 years (range 1-25); the main clinical reason for a biopsy was proteinuria. R enal function changes ranged from slight elevation of serum creatinine to uraemia. In addition 9 original papers, including our own material 580 patients were examined. $O \mathrm{n}$ the basis of careful morphological evaluation according to international criteria, no patient exhibited an unequivocal sign of non-diabetic glomerular disease. Two patients had strongly but not completely convincing evidence of glomerulonephritis. O ne patient had some evidence of glomerulonephritis. These
3 patients also exhibited diabetic lesions. O ne patient with end-stage renal disease showed evidence of interstitial nephropathy without glomerular lesions. Thus, in 4 patients evidence of non-diabetic lesions was found. In the remaining 29 patients typical diffuse $(n=9)$ or nodular $(n=20)$ diabetic lesions were found. Twenty patients showed evidence of diabetic retinopathy. One of the patients with evidence of non-diabetic renal disease had simplex retinopathy. In the literature a considerable bias exists towards including patients with non-diabetic renal disease. In non-biased materials with proteinuria the prevalence of non-diabetic renal disease is very similar to our series. In microalbuminuric patients non-diabetic renal disease seems to be very rare. It can be concluded that in our material non-diabetic renal disease is uncommon in NIDDM patients, even if a clinician has suggested renal disease of other origin. A considerable bias towards including non-diabetic renal disease in NIDDM patients exists in the literature. The indication for biopsy should be evaluated carefully, and biopsy should by no means be routinely performed in NIDDM patients with proteinuria. [Diabetologia (1996) 39: 1638-1645]

Keywords Non-insulin-dependent diabetes mellitus, proteinuria, diabetic nephropathy, renal biopsy.
Corresponding author: Professor C.E . M ogensen, M edical D epartment $M$ ( $D$ iabetes and $E$ ndocrinology), A arhus Kommunehospital, DK -8000 A rhus C, D enmark

A bbreviations: GN, Glomerulonephritis; IDDM, insulin-dependent diabetes mellitus; NID D M , non-insulin-dependent diabetes mellitus; LM, light microscopy; EM, electron microscopy; PA S, periodic acid-Schiff.
A bout $20-40 \%$ of patients suffering from diabetes mellitus eventually develop diabetic renal disease with characteristic changes in the glomeruli and vessels, during the years progressing toward end stage renal disease. These days fewer may develop advanced renal disease, due to more active intervention [1]. A s could be expected, diabetic patients may also suffer from other renal diseases. A large number of renal biopsy studies, mainly case studies, have shown the 
coincidence of diabetes and glomerulonephritis (GN). On the other hand, autopsy studies have shown that complicating glomerular disease is rare $[2,3]$ and probably does not exceed the prevalence in the background population. Tubulointerstitial disease, which is common in the later stages of diabetic renal disease, has previously been regarded as evidence of complicating chronic pyelonephritis, but, according to recent findings, tubular atrophy, interstitial fibrosis and interstitial mononuclear cell infiltration are related to vascular changes and are interpreted as consequences of chronic ischaemia due to the diabetic glomerular and vascular changes prominent in advanced diabetic renal disease $[4,5]$.

Complicating $\mathrm{GN}$ in diabetes has been described in several reports [6-9], $M$ onga et al. [7] reviewed biopsy studies up to 1989. It is generally presumed that GN complicating insulin-dependent diabetes (IDDM) is comparatively rare $[10,11]$, probably around $2-3 \%$ in unselected cases with proteinuria and a diabetes duration of more than 10 years ( $M$. $M$ auer, personal communication). Recently, it has been reported that $\mathrm{GN}$ may be more common in non-insulin-dependent diabetes (NIDDM) [11-17]; however, published data are conflicting $[18,19]$.

The aim of our study is to present a consecutive series of renal biopsies from patients in D enmark with NIDDM and to undertake an analysis of the literature.

\section{The Århus series}

Patients. We identified 33 percutaneous renal biopsies from 33 patients with a clinical diagnosis of NIDDM from 1988 to 1995 from the files of the U niversity Institute of Pathology, A rhus, Denmark. A II patients had been referred to a nephrology department. The indication for biopsy was a clinical presentation that, in the view of the nephrologist, might indicate presence of renal disease other than diabetic nephropathy. Patients were classified as having NIDDM according to World Health O rganization (WHO) criteria [20] by studying case reports. IDDM patients were not included in this study. Clinical data according to the serum creatinine level are shown in Table 1. $\mathrm{H}$ aematuria was found for some of the patients, but was not listed as an indication for biopsy. D iabetic retinopathy was noted in 20 patients (Table 1). No special clinical features distinguished the patients who, according to the findings in the biopsy, were regarded as having possible non-diabetic kidney disease.

The biopsies. Preparation for light microscopy (LM) was performed according to a standard routine procedure [21]. Formalin-fixed percutaneous biopsies were embedded in paraffin wax and serial sections stained with silver methenamin-haematoxylin, periodic acid
Schiff (PA S) haematoxylin, trichrome M asson, haematoxylin and eosin, and alkalic Congo red for amyloid. A II biopsies contained sections of at least 10 glomeruli.

A II biopsies were investigated immunohistochemically for immunoglobulins G, M, A , complement C 3, fibrinogen and albumin, 19 using immunofluorescence microscopy on frozen tissue. In 14 biopsies the frozen part of the biopsy did not contain glomeruli. These were investigated immunohistologically with the peroxidase method on paraffin sections.

Plastic-embedded material from 18 biopsies contained glomeruli which were studied by electron microscopy (EM).

D iabetic glomerular changes were diagnosed according to generally accepted criteria [22] and scored semiquantitatively on PA S-stained sections in a blinded manner, i.e. without knowledge of the clinical conditions. D iffuse changes were scored: $D 1$, if there was a slight; D 2, a moderate and D 3, a severe widening of the mesangial matrix without formation of nodules. No biopsy had completely normal glomeruli (D 0). The score N 0 indicates no nodules; N 1 is the presence of a few small nodules in some of the glomeruli. N2 indicates unequivocal presence of one or more classic, acellular nodules in many glomeruli and in biopsies scored $\mathrm{N} 3$ large nodules were present in most glomeruli. I $n$ biopsies with N 2 and N 3 there was also marked ischaemic sclerosis of the glomerular tuft. All the biopsies showed arteriolar hyaline changes to a degree corresponding to diffuse and nodular glomerulopathy.

Interstitial fibrosis was scored I1, if weak and focal; 12, if moderate, diffuse and 13 if severe, diffuse. Tubular atrophy was present to a degree corresponding with the fibrosis and was not scored separately.

Criteria for diagnosis of $\mathrm{GN}$ were those of the WHO classification [23].

\section{Results}

Light microscopy. The structural findings are included in Table 1 and shown in Table 2. Typical diabetic glomerulopathy and arteriolar hyalinosis without evidence of $\mathrm{GN}$ or other non-diabetic renal disease were found in 29 biopsies.

I mmunohistology. I gG in a linear pattern, of weak or moderate intensity associated with an identical reaction for albumin was present in the glomerular tuft in many biopsies. This is a well-known unspecific feature in diabetic glomerulopathy. I gM and C 3 in a segmental, focal, granular pattern of weak or moderate intensity, which has also been reported in uncomplicated diabetic nephropathy, were present in the glomeruli in two biopsies. These showed no deposits on E M . M oderate reactions for I gM and C 3 in arterioles, 
Table 1. Characteristics of NIDD M patients who underwent renal biopsy

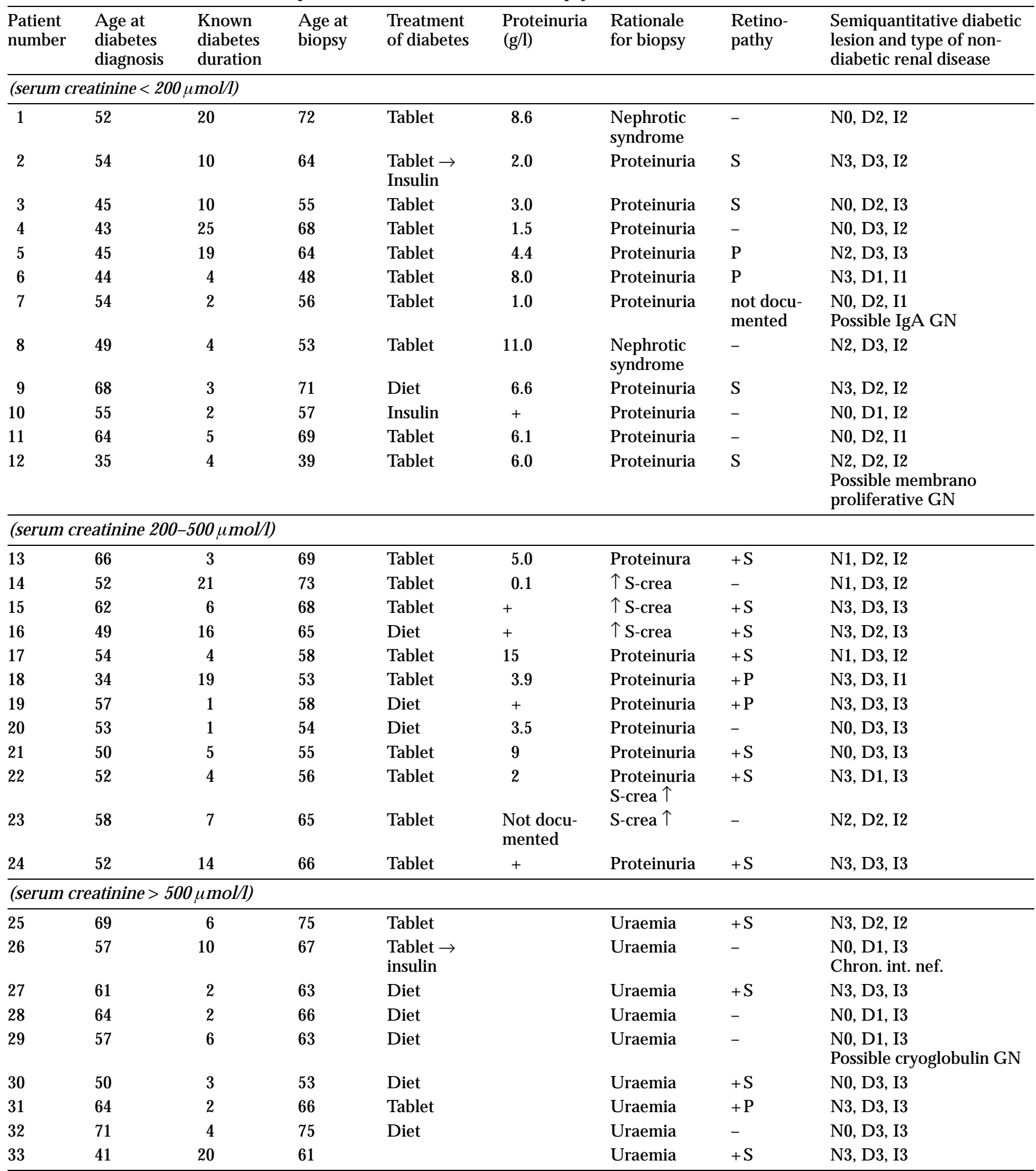

S, simplex; $\mathrm{P}$, proliferative; - no retinopathy; $\mathrm{N}$, nodular glomerular change; $\mathrm{D}$, diffuse glomerular change; 1 , interstitial fibrosis

a common phenomenon in hypertension, were seen in several biopsies.

In summary, only non-specific staining was seen and this technique did not lead to the unequivocal diagnosis of $\mathrm{GN}$ in any case.
E lectron microscopy. In two biopsies, dense deposits were seen, patient 7 and patient 29 (Table 1). A II the others showed uncomplicated diabetic glomerular changes. 
Table 2. H istological diagnoses of 33 biopsies from patients with NID D M (A rhus series)

\begin{tabular}{llr}
\hline Pure diabetic change & (nodular) & 20 \\
& (diffuse) & 9 \\
Diabetic change plus possible glomerulonephritis & \\
Chronic interstitial nephritis (idiopathic) & 3 \\
& 1 \\
& 33 \\
\hline
\end{tabular}

a $O$ ne possible case of cryoglobulinaemic $G N$, one possible I gA GN, (mesangial deposits on EM but no deposits on immunofluorescence microscopy. O ne biopsy showed membranoproliferative glomerulonephritis on LM but no deposits were seen on EM or immunohistochemistry

Patients with possible non-diabetic disease. O ne patient (Table 1, patient 26) had diffuse interstitial fibrosis, tubular atrophy and moderate, diffuse mononuclear cell infiltration, which could not be explained by the diffuse diabetic glomerulopathy which was very slight. No immunodeposits were seen in the glomeruli or tubular basement membranes on EM or immunohistochemistry. The aetiology of this chronic interstitial nephritis is unknown. A nother biopsy (patient 28 Table 1) also had severe fibrosis and a score of $D 1$, but in this case there was severe hyaline arteriolosclerosis and 5 of the 10 glomeruli in the biopsy were totally sclerosed. The remaining glomeruli had slight diffuse mesangial widening as well as segmental sclerotic changes of the ischaemic type. This histology was considered to be entirely compatible with a late stage of diabetic nephropathy. The absence of nodules in this case as well as in others in the group, with severe reduction of renal function, is not unusual since nodules tend to disappear with marked glomerular obsolescence [24].

Possible complicating $\mathrm{GN}$ together with diabetic glomerular changes were found in three patients.

Patient 7 (Table 1) had moderate diffuse diabetic glomerulopathy but no focal or diffuse proliferative changes by LM . O n E M some mesangial regions contained dense deposits but many others were without abnormal depositions. No deposits were seen on immune peroxidase. We regard this as a possible case of IgA nephropathy. The patient had slight proteinuria but close to normal renal function.

Patient 29 (Table 1) was a 63-year-old man who had known diabetes for 6 years. The renal biopsy showed only slight diffuse diabetic changes but severe glomerular sclerosis with focal adhesions and mesangial proliferation, interstitial fibrosis and tubular atrophy. A t biopsy he was being treated with dialysis and had proteinuria of $5 \mathrm{~g} / \mathrm{l}$ as well as microscopic haematuria. The sedimentation rate was about $100 \mathrm{~mm}$ and there was cryoglobulinaemia. I mmunohistochemistry with the peroxydase technique was negative. On EM sclerosing glomerular changes were seen with scattered mesangial and subendothelial dense deposits which were not fibrillary, crystalline or otherwise organized.
The diagnosis was sclerosing $\mathrm{GN}$. A t this late stage, the original type is uncertain, but it was considered probable that this was a case of cryoglobulinaemic membranoproliferative $\mathrm{GN}$.

The third patient (Table 1, patient 12) was a 39year-old male who had been diabetic for 4 years. A t biopsy he had proteinuria of $6 \mathrm{~g} /$ day, and retinopathy. The renal biopsy showed nodular glomerular changes, moderate mesangial cell proliferation and on silver staining peripheral mesangial interposition. Immunofluorescence microscopy and EM did not show immunodeposits. On L M this patient had membranoproliferative $\mathrm{GN}$ but in the absence of immunodeposits, the basis for this diagnosis was not convincing and it cannot be excluded that the LM changes could be associated with diabetic glomerulopathy.

D ue to the reservations discussed, we have interpreted these three cases as possible, but not unquestionable G N .

\section{Discussion and analysis of the literature}

$M$ any sporadic cases of coexistence of diabetic renal disease with other renal diseases have been published, but only recently have studies been made of cases of NIDDM in particular. Nine reports of renal biopsy studies specifically dealing with NIDDM have been identified [11-19]. The main results are presented in Tables 3, 4 and 5. A recent populationbased, controlled, cross-sectional study by Wirta et al. [25] reported on the albumin excretion rate in 296 recently diagnosed, long-term NID D M patients. This study is not included in the Tables since a renal biopsy was only obtained in 16 patients. These biopsies showed either normal structure (4 biopsies) or diffuse diabetic glomerulopathy ( 12 biopsies) and no complicating renal disease was found. In a recent study by Fioretto et al. [18] of 34 microalbuminuric patients, the authors did not find any case of renal disease other than diabetes. The results in microalbuminuric patients $[18,19,25,26]$ are very consistent: no evidence of non-diabetic renal disease.

\section{G lomerulonephritis}

It appears from Table 3 and 4 that there were great variations in the results. The rates of $\mathrm{GN}$ vary between 0 and $66 \%$ and those of other complicating renal diseases between 0 and $20 \%$. These diverging results could be due to several factors.

Selection criteria. Most of the studies are presentations of selected series of renal biopsies and were as our own - based upon cases identified retrospectively from renal biopsy files of patients suffering from NIDDM [11-13, 15-17]. The patients were 
Table 3. R eports in the literature of complicating renal disease in NID D M

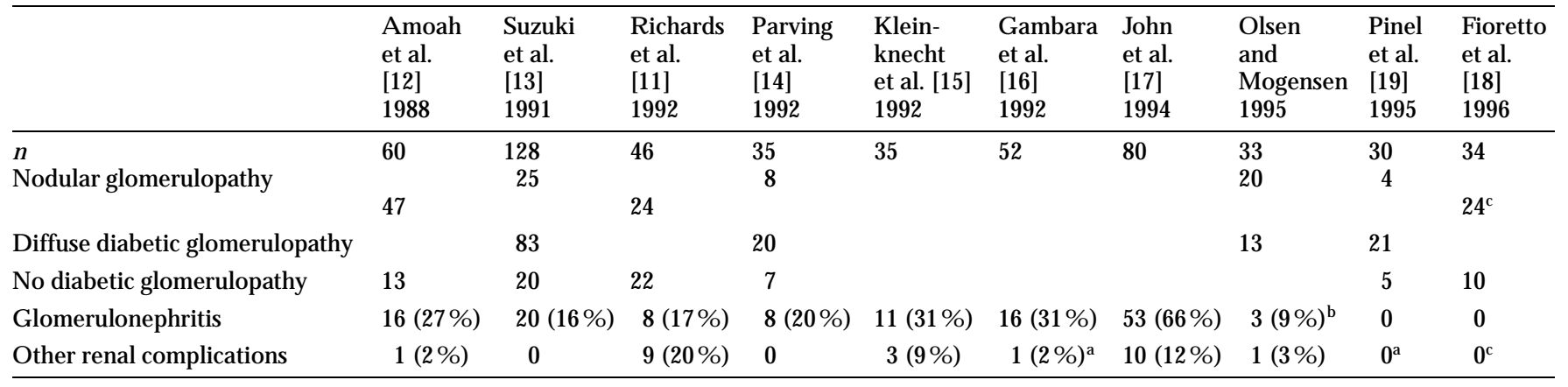

a Exclusive ischaemic changes and "chronic pyelonephritis";

${ }^{b}$ possible, but uncharacteristic;

c 14 biopsies had "atypical" pattern: mild diabetic changes with disproportionately severe chronic tubulointerstitial and arteriolar changes

Table 4. G lomerulonephritis in NID D M

\begin{tabular}{|c|c|c|c|c|c|c|c|c|c|}
\hline & $\begin{array}{l}\text { A moah } \\
\text { et al. } \\
{[12]} \\
1988\end{array}$ & $\begin{array}{l}\text { Suzuki } \\
\text { et al. } \\
\text { [13] } \\
1991\end{array}$ & $\begin{array}{l}\text { R ichards } \\
\text { et al. } \\
{[11]} \\
1992\end{array}$ & $\begin{array}{l}\text { Parving } \\
\text { et al. } \\
\text { [14] } \\
1992\end{array}$ & $\begin{array}{l}\text { K lein- } \\
\text { knecht } \\
\text { et al. [15] } \\
1992\end{array}$ & $\begin{array}{l}\text { G ambara } \\
\text { et al. } \\
{[16]} \\
1992\end{array}$ & $\begin{array}{l}\text { John } \\
\text { et al. } \\
{[17]} \\
1994\end{array}$ & $\begin{array}{l}\text { O Isen } \\
\text { and } \\
\text { M ogensen } \\
1995\end{array}$ & $\begin{array}{l}\text { A ll } \\
\text { authors }\end{array}$ \\
\hline $\begin{array}{l}\text { G lomerulonephritis } \\
\text { G }\end{array}$ & $\begin{array}{l}60 \\
27 \%\end{array}$ & $\begin{array}{l}128 \\
16 \%\end{array}$ & $\begin{array}{l}46 \\
17 \%\end{array}$ & $\begin{array}{l}35 \\
23 \%\end{array}$ & $\begin{array}{l}35 \\
31 \%\end{array}$ & $\begin{array}{l}52 \\
31 \%\end{array}$ & $\begin{array}{l}80 \\
66 \%\end{array}$ & $\begin{array}{l}33 \\
9 \% \text { a }\end{array}$ & $\begin{array}{l}533 \\
25 \%\end{array}$ \\
\hline $\begin{array}{l}\text { Types } \\
\text { - Endocapillary, post-infectious } \\
\text { - M embranous } \\
\text { - IgA, Schönlein-H enoch } \\
\text { - Focal proliferative } \\
\text { - Crescentic, anti-GB M, } \\
\text { rapid progressive } \\
\text { - M esangial proliferative } \\
\text { - M embranoproliferative } \\
\text { - Systemic lupus erythematosus GN } \\
\text { - M inimal change } \\
\text { - O ther }\end{array}$ & $\begin{array}{l}4 \\
1 \\
1 \\
2 \\
1\end{array}$ & $\begin{array}{r}7 \\
13\end{array}$ & $\begin{array}{l}3 \\
1 \\
1 \\
1 \\
\\
1 \\
1\end{array}$ & 4 & $\begin{array}{l}5 \\
1 \\
5\end{array}$ & $\begin{array}{l}6 \\
2 \\
2 \\
2 \\
2\end{array}$ & $\begin{array}{r}14 \\
6 \\
6 \\
5 \\
\\
5 \\
4 \\
\\
1 \\
12\end{array}$ & (1) & $\begin{array}{r}22 \\
26 \\
26 \\
13 \\
12 \\
8 \\
2 \\
3 \\
20 \\
3\end{array}$ \\
\hline n with glomerular disease & 16 & 20 & 8 & 1 & 11 & 16 & 53 & 3 & 135 \\
\hline
\end{tabular}

a Possible glomerulonephritis

${ }^{b}$ Pinel et al. and Fioretto et al. reported no cases of glomerulitis buminuric patients only

referred to a nephrology department, and in some reports it was explicitly stated that the biopsies were made due to the presence of symptoms and signs which were considered to be caused by diseases other than diabetes. The inclusion criteria were stated in detail in only one study [17]; presence of haematuria or nephrotic syndrome, abrupt proteinuria sometimes in the nephrotic range, rapidly progressive or unexpected renal failure (the diabetes was, in these cases, detected after the renal biopsy) with symmetrical kidneys of normal size by scintigraphy or angiography, but it is probable that criteria such as these were also used in the other studies. It is clear that such selection criteria will favour inclusion of complicating renal disease and they at least partly explain the high complication rate in some of these reports. Our own series was also biased by the inclusion of patients with clinical signs not completely characteristic of diabetic renal disease, but nevertheless having a low complication rate of $9 \%$.

In contrast to these reports, Pinel et al. [19] have excluded all patients with clinical renal disease other than the presence of NIDDM and micro- or macroalbuminuria. It is interesting that this particular study has no complicating renal disease. The biopsy studies of Fioretto et al. [18] on microalbuminuric patients, which included $\mathrm{EM}$ and immunofluorescence microscopy, were performed on the basis of a research protocol rather than clinical indications. They found no cases of any definable renal disease other than diabetes.

The only report based on a cross-sectional, consecutive series of unselected patients with NIDDM and albuminuria ( $\geq 300 \mathrm{mg} / 24 \mathrm{~h}$ ) is that of Parving et al. [14] which will be discussed below. 
Table 5. N on-glomerular diseases in NID D M

\begin{tabular}{|c|c|c|c|c|c|c|c|c|}
\hline & $\begin{array}{l}\text { A moah } \\
\text { et al. [12] } \\
1988\end{array}$ & $\begin{array}{l}\text { Suzuki } \\
\text { et al. [13] } \\
1991\end{array}$ & $\begin{array}{l}\text { R ichards } \\
\text { et al. [11] } \\
1992\end{array}$ & $\begin{array}{l}\text { Parving } \\
\text { et al. [14] } \\
1992\end{array}$ & $\begin{array}{l}\text { K leinknecht } \\
\text { et al. [15] } \\
1992\end{array}$ & $\begin{array}{l}\text { G ambara } \\
\text { et al. [16] } \\
1992\end{array}$ & $\begin{array}{l}\text { John } \\
\text { et al. [17] } \\
1994\end{array}$ & $\begin{array}{l}\text { Olsen and } \\
\text { M ogensen } \\
1995\end{array}$ \\
\hline $\mathrm{n}$ total & 60 & 128 & 46 & 35 & 35 & 52 & 80 & 33 \\
\hline $\begin{array}{l}\text { Non-glomerular diseases } \\
\text { - A myloidosis } \\
\text { - M yeloma } \\
\text { - Cortical necrosis } \\
\text { - Tubular necrosis } \\
\text { - Interstitial nephritis } \\
\text { - Papillary necrosis } \\
\text { - A theroma emboli } \\
\text { - H ypertensive change } \\
\text { - Sarcoidosis }\end{array}$ & 1 & & $\begin{array}{l}3 \\
2 \\
1\end{array}$ & & 1 & 1 & 2 & 1 \\
\hline Total & 1 & 0 & 9 & 0 & 3 & 1 & 10 & 1 \\
\hline
\end{tabular}

G eographical differences. The most excessive rate of glomerulitis (Table 2) is that of J ohn et al. [17] which can be explained as due to the fact that these patients were from a tropical area (south India) where $\mathrm{GN}$ is said to be particularly common. This applies especially to acute infectious $\mathrm{GN}$ which has become comparatively rare in biopsy materials from western countries.

Criteria for diagnosis of $\mathrm{G} \mathrm{N}$. In the report of Parving et al. [14] four patients were considered to have minimal lesion nephropathy. This term is somewhat ambiguous, embracing conditions such as minimal change nephrotic syndrome, isolated proteinuria or pure haematuria with glomeruli which are normal or show only minor abnormalities [23]. The patients of Parving et al. apparently had no nephrotic syndrome and no haematuria was noted. Normal glomeruli by $L M$ and no deposits by immunofluorescence or $E M$ is, however, completely compatible with early diabetic glomerulopathy with slight or even moderate albuminuria and we cannot accept that these four patients were suffering from non-diabetic renal disease. A mong four other patients considered to have $G N$, one had mesangial widening and some adhesions between the tuft and the capsule of B owman. In three other patients mesangial proliferation was described; one with $\mathrm{C} 3$ but no immunoglobulins; the other two had IgA and IgM deposits in the glomerular tuft. These cases are uncertain since some mesangial hypercellularity $[27,28]$ and adhesions may be part of the diabetic glomerulopathy. The three cases with a diagnosis of mesangioproliferative glomerulonephritis were included in the group which were investigated by $E M$. These biopsies did not contain dense deposits in the glomeruli [28]. If, however, all the four patients are accepted as having complicating $\mathrm{GN}$, but not the four cases with minimal changes, the prevalence of complicating renal disease, unrelated to diabetes in this cross-sectional, non-selected material, is 4 of $35(11 \%)$. The three cases of $\mathrm{GN}$ in our material are also equivocal, but if these are accepted, the rate of complicating $\mathrm{GN}$ in our material is $9 \%$.

\section{O ther complicating diseases}

The spectrum of these diagnoses (Table 5 ) reflects well-known (although comparatively rare) complications of diabetes such as papillary necrosis and atheromatous emboli. 0 ther renal diseases (e. g. amyloidosis, myeloma) represented are common in the age range in which NIDDM occurs. It is probable that these complications are unrelated to the diabetic state.

Tubulointerstitial changes. It is well-established that long-term diabetic nephropathy is associated with prominent interstitial changes consisting of interstitial fibrosis, tubular atrophy and mononuclear cell infiltration. Formerly these changes were interpreted as evidence of complicating chronic pyelonephritis [2]. It appeared, however, that these changes were correlated to the renal microvascular alterations characteristic of long-term diabetes, and it is now generally held that they are due to chronic ischaemia $[4,5]$. G ambara et al. [16] described a special group of patients with diabetic renal disease in which the interstitial changes were not clearly correlated with glomerular or vascular lesions. Conceivably such changes may be due to diabetes but related to pathologies other than chronic ischaemia, but this is unknown.

The presence in one biopsy of diffuse interstitial fibrosis and mononuclear cell infiltration without or with only weak diabetic nephropathy, as in our case (patient 26, Table 1), cannot easily be explained by ischaemia. If the fibrosis had been due to atherosclerotic narrowing of a larger vessel not represented in the biopsy, glomerular sclerosis or collapse of the capillary could be expected. We have interpreted this case as idiopathic chronic interstitial nephritis. Such cases have also been described in another series 
(Table 5). This disease is rare and probably represents a coincidence, unrelated to diabetes.

\section{Conclusion}

The high rate of non-diabetic, complicating renal disease in NIDDM which has been reported in several biopsy series is almost certainly due to selection of patients with clinical renal disease other than diabetic nephropathy. The comparatively low complication rate in the unselected series of Parving et al. (if we are right in reducing it to about $10 \%$ as discussed above), and even in our own series, consisting of patients referred to nephrology departments, does not support the view that NIDDM is associated with a high rate of non-diabetic renal complications. None of the studies published up to now permit the conclusion that complicating renal disease is more frequent than in the background population. In microalbuminuric patients, the picture seems clear: non-diabetic disease is rare. The real complication rate can only be calculated using a large series of renal biopsies from non-selected NIDDM patients compared with a comparable cross-section of non-diabetic patients and such an investigation may not be ethically acceptable. H owever, unselected autopsy studies suggest a very low prevalence $[2,3]$.

O ur series show (as do many others) that NIDD M patients - even in a fairly young age-range - may have advanced glomerulopathy after only a few years of known duration of diabetes. Clinical proteinuria and microalbuminuria was seen in 5.6 and $31.2 \%$ of cases in a large series with newly diagnosed N IDD M in clinical practice in Denmark [29]. It is likely that this mainly reflects a long period of undiagnosed diabetes typical for NIDDM patients [30]. In this study [29] renal biopsy was not contemplated in the 72 patients presenting with an albumin/creatinine ratio corresponding to clinical proteinuria. Their prognoses appear, however, to be poor [31] but may, in our opinion, not be affected by the results of a renal biopsy.

B ased on the published literature, we do not agree with the view proposed by some authors that all patients with NIDDM and renal impairment should have a renal biopsy as part of their investigation. The data of J ohn et al. [17] show that significant clinical renal disease, other than diabetes, was almost always present in patients with complications. To this may be added that effective treatment of $\mathrm{GN}$ is restricted to a few forms (minimal change nephrotic syndrome and crescentic GN [32]. It is noteworthy that none of the eight patients, whom in the study of Parving et al. [14] were thought to suffer from GN, needed special therapy.

In our opinion renal biopsy should be performed in a small group of patients with NIDDM (as well as
IDD M ), such as those manifesting proteinuria in the nephrotic range at a point during the course of diabetes where this is not expected: with sudden increase in urinary protein excretion; with rapidly progressive renal failure; or having other nephrologic or urologic symptoms which would need investigation with renal biopsy in non-diabetic patients.

A cknowledgements. The authors wish to thank drs. H.E.H ansen, M.D., K.Sølling, M.D., N.A.L arsen, M.D., and R.S.Pedersen, M.D. for providing clinical data from some of the patients.

\section{References}

1. M ogensen C, K eane W, B ennett P et al. (1995) Prevention of diabetic renal disease with special reference to microalbuminuria. Lancet 346: 1080-1084

2. Ditscherlein G (1969) Nierenveränderungen bei Diabetikern.J ena: G ustav Fischer Verlag

3. Waldherr R, Ilkenhans C, R itz E (1992) How frequent is glomerulonephritis in diabetes mellitus type II? Clin N ephr 37: 271-273

4. B ohle A, Wehrmann M, Bogenschütz B, M üller C (1991) The pathogenesis of chronic renal failure in diabetic nephropathy. Path R es Pract 187: 251-259

5. B ader R, B ader H, G rund K, M ackensen- $H$ ahn S, C hrist H, B ohle A (1980) Structure and function of the kidney in diabetic glomerulosclerosis. Correlations between morphological and functional parameters. Path R es Pract 167: 204-216

6. Chihara J, Takebayashy S, Taguche T, Y okohama K, Harada T, Naito S (1986) Glomerulonephritis in diabetic patients and its effect on the prognosis. N ephron 43: 45-49

7. M onga $G, M$ azzucco $G$, diB elgioso $G$, Confalonieri $R$, Sacche G, Bertani T (1989) Pattern of double glomerulopathies: a clinicopathologic study of superimposed glomerulonephritis on diabetic glomerulosclerosis. M od Pathol 2: 407-414

8. Taft J, Billson V, Nankervis A, K incaid-Smith $\mathrm{P}, \mathrm{M}$ artin $\mathrm{F}$ (1990) A clinical-histological study of individuals with diabetes mellitus and proteinuria. Diab M ed 7: 215-221

9. K incaid-Smith P, Whitworth J (1994) Hematuria and diabetic nephropathy. In: Mogensen $C$ (ed) The kidney and hypertension in diabetes mellitus. K luwer A cademic Publishers, Boston pp 151-160

10. M auer S, Steffes M, E llis E, Sutherland D, B rown D, G oetz F (1984) Structural-functional relationship in diabetic nephropathy. J Clin Invest 74: 1143-1155

11. R ichards N, G reaves I, L ee S, H owie A, A du D, M ichael J (1992) Increased prevalence of renal biopsy findings other than diabetic glomerulopathy in type II diabetes mellitus. N ephr D ial Transplant 7: 397-399

12. A moah E, G lickman J, M alchoff C, Sturgill B, Kaiser D, Bolton W (1988) Clinical identification of nondiabetic renal disease in diabetic patients with type I and type II disease presenting with renal dysfunction. A m J Nephrol 8: 204-211

13. Suzuki Y, U eno M, Hayashi $H$ et al. (1994) A light microscopic study of glomerulosclerosis in Japanese patients with noninsulin-dependent diabetes mellitus and histological features. Clin Nephr 42: 155-162

14. Parving $\mathrm{H}-\mathrm{H}, \mathrm{G}$ all $\mathrm{M}-\mathrm{A}$, Skøtt $\mathrm{P}$ et al. (1992) Prevalence and causes of albuminuria in non-insulin-dependent diabetic patients. $\mathrm{K}$ idney Int 41: 758-762 
15. Kleinknecht D, Bennis D, JJ, A Itman A et al (1992) Increased prevalence of non-diabetic renal pathology in type II diabetes mellitus. N ephrol D ial Transplant 7: 1258-1259

16. G ambara V, M ecca G, R emuzzi G, B ertani T (1993) H eterogenous nature of renal lesions in type II diabetes. J A m Soc N ephr 3: 1458-1466

17. John G, D ate A, Korula A, Jeyaseelan L, Shastry J, Jacob C (1994) Nondiabetic renal disease in noninsulin-dependent diabetics in a South Indian hospital. Nephron 67: 441-443

18. Fioretto $P, M$ auer $M, B$ rocco $E$ et al. (1996) Patterns of renal injury in type 2 (non-insulin dependent) diabetic patients with microalbuminuria. Diabetologia 39 [Suppl 2]: S31-S 38

19. Pinel N, Fadel BF, B ilous R, Corticelli P, H alimi S, Cordonnier D (1995) Renal biopsies in 30 micro- and macroalbuminuric non-insulin dependent (NID D M ) patients: heterogeneity of renal lesions. E uropean D iabetic N ephropathy Study $\mathrm{G}$ roup $\mathrm{H}$ eidel berg

20. WH O Study G roup (1994) Prevention of diabetes mellitus. WHO Technical R eport Series

21. Brun C, O Isen S (1981) A tlas of renal biopsy. W B Saunders, Philadelphia

22. OIsen S (1994) Light microscopy of diabetic glomerulopathy: the classic lesion. In: Mogensen C (ed) The kidney and hypertension in diabetes mellitus. 2nd ed. K luwer A cademic Publishers, Boston pp 141-150

23. Churg J, Bernstein J, G lassock R (1995) R enal disease: classification and atlas of glomerular diseases. I gaku-Shoin, New York, Tokyo
24. Thomsen A (1965) The kidney in diabetes mellitus, M unksgaard, Copenhagen

25. Wirta O, Pasternak A, M ustonen J, O ksa H, Koivula T, H elin $\mathrm{H}$ (1995) A lbumin excretion rate and its relation to kidney disease in non-insulin-dependent diabetes mellitus. J Int M ed 237: 367-373

26. B ertani T, G ambara V, R emuzzi G (1996) Structural basis of diabetic nephropathy in microalbuminuric non-insulindependent diabetes mellitus patients. A light microscopic study. D iabetologia 39 [Suppl 2]: S87-S 90

27. G undersen H,$\varnothing$ sterby R (1977) G lomerular size and structure in diabetes mellitus. II. L ate abnormalities. Diabetologia 13: 43-48

28. $\varnothing$ sterby R, G all M-A, Schmitz A, N ielsen F, Nyberg G, Parving $\mathrm{H}-\mathrm{H}$ (1993) Glomerular structure and function in proteinuric type 2 (non-insulin-dependent) diabetic patients. D iabetologia. 36: 1064-1070

29. Olivarius $\mathrm{N}$ deF, A ndreasen A H, K eiding N, M ogensen CE (1993) E pidemiology of renal involvement in newly diagnosed middle-aged and elderly patients. Cross-sectional data from the population-based study "Diabetes Care in general Practice" D enmark. D iabetologia 36: 1007-1016

30. H arris M, K lein R, Welborn T, K nuiman M (1992) O nset of NIDD M occurs at least 4-7 years before clinical diagnosis. D iabetes Care 15: 815-819

31. Schmitz A (1995) Nephropathy in non-insulin dependent diabetes mellitus and perspectives for intervention. Diab N utr M etab 7: 135-148

32. M ason P, Pusey C (1994) Glomerulonephritis: diagnosis and treatment. BM J 309: 1557-1563 